\title{
Prediction of Self-Care Behavior Using Extended Theory of Reasoned Action among Women with Type 2 Diabetes Referred to Health Centers of Mashhad
}

\begin{abstract}
Background and objective: The successful management of diabetes relies on performing individual designed self-care activities to control symptoms and avoid complications; but one of the causes of diabetes complications is lack of self-care by diabetic patients. Therefore this study was conducted to predict self-care behavior using extended theory of reasoned action (ETRA) among women with type 2 diabetes.

Materials and methods: In this cross-sectional and descriptive-analytical study, 300 women with type 2 diabetes referred to government health centers in the city of Mashhad were selected by multistage cluster sampling method. Data gathering tools were ETRA questionnaire and Toobert and colleagues' brief scale of self-care behaviors'. For data analysis was used by descriptive and inferential statistics through SPSS 21 . For prediction self-care behavior, as dependent variables, was used from multiple linear regression (using the Enter and backward models).

Results: The self-efficacy was the most important structure for predicting of self-care intention. Results of regression showed that $55 \%$ the variance of behavioral intention and $24 \%$ the variance in self-care behavior can be predicted by the model.

Conclusion: The theory of reasoned action along with self-efficacy is suitable for predicting the self-care behaviors in diabetic women and self-efficacy is considered an important structure in determining self-care behaviors.

Paper Type: Research Article.

Keywords: Extended theory of reasoned action (ETRA), Self-efficacy, Self-care behaviors, Type 2 diabetes, Mashhad.
\end{abstract}

Citation: Taghipour A, Moshki M, Mirzaei N. Prediction of self-care behavior using extended theory of reasoned action among women with type 2 diabetes referred to health centers of Mashhad. Iran J Health Educ Health Promot. Summer 2016;4(2): 120-129.
Ali Taghipour

Associate Professor, Health Sciences Center, Dept. of Biostatistics and Epidemiology, School of Health, Mashhad University of Medical Sciences (MUMS), Mashhad, Iran

Mahdi Moshki

Associate Professor of Health Education and Promotion, Dept. of Public Health, School of Health Sciences; Social Development \& Health Promotion Research Center, Gonabad University of Medical Sciences (GUMS), Gonabad, Iran

Nasim Mirzaei

*MSc. in Health Education and Health Promotion, Student Research Committee, Department of Health and management, School of Health, MUMS, Mashhad, Iran (Corresponding Author) mirzaeinasim78@gmail.com

Received: 17 August 2015 Accepted: 08 September 2016 
يشيشبينى رفتار خودمراقبتى با استفاده از نظريه عمل منطقى توسعهيافته در زنان ديابتى نوع دو مراجعه كننده به مراكز بهداشتى-درمانى دولتى شهر مشهد على تقى تيور مانشيار مركز تحقيتان

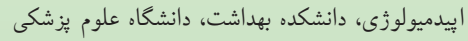
مشهد، مشهد، ايران

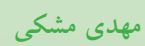
دكتراى تخصصى آموزش بهداشت و ارتقاى سلامت،

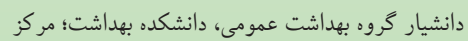
تحقيقات توسعه اجتماعى و ارتقاء سلامت، دانياء دانشكاه علوم يزشكى كناباد، كناباد، ايران

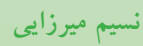
* كارشناسى ارشد آموزش بهداشت و ارتقاى سلامت،

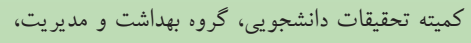
دانشكده بهداشت، دانشكاه علوم يز شكى مشهد، مشهد،

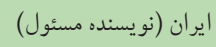
mirzaeinasim@gmail.com

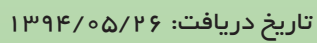

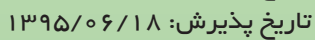

\section{:}

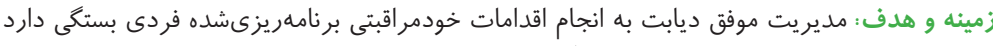

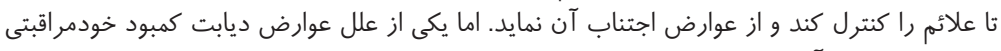

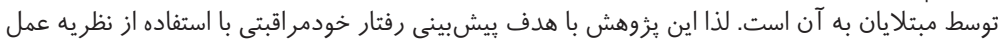

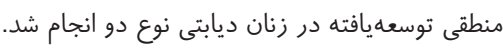

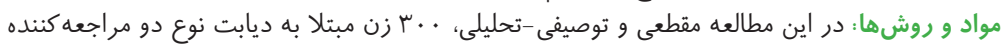

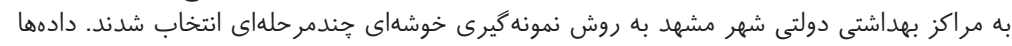

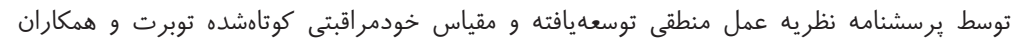

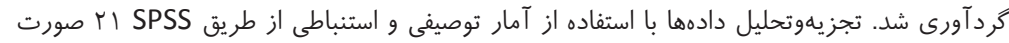

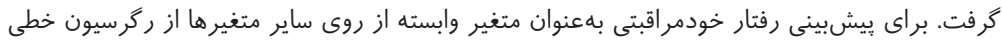

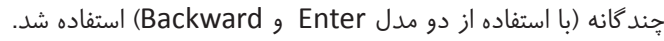

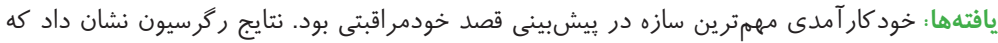

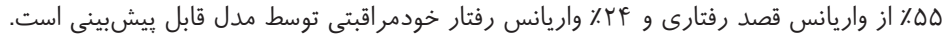

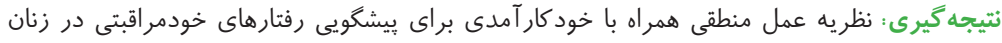

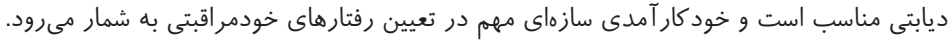

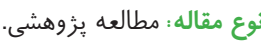
كليدوازه : نظريه عمل منطقى توسعهيافته، خود كار آمدى، رفتار خودمراقبتى، ديابت نوع دو، مشهد.

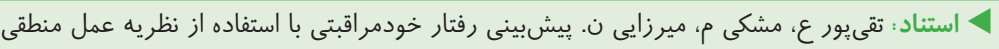

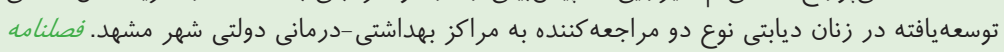

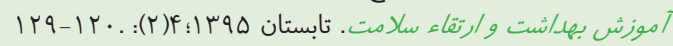




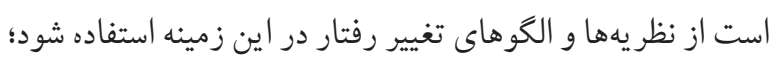
زيرا نظر يهها و الخوها، عوامل اصلى كه رفتار را تحت تأثير قرار مىدهند، شناسايى كردهو روابط اين عوامل را تعيين مى كند (^). نظريه عمل منطقى ` يكى از موفقترين نظريههاى تغيير رفتار

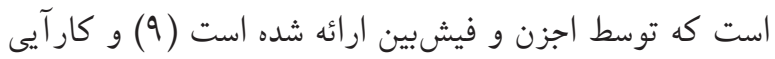

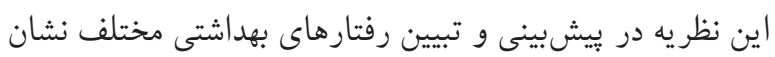

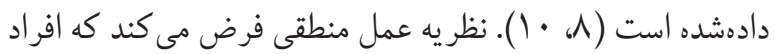
به هنگام تصميم گيرى در مشاركت كردن يا نكردن يك رفتار،

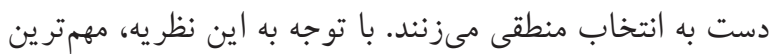

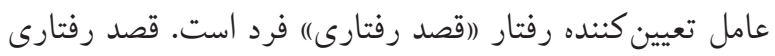

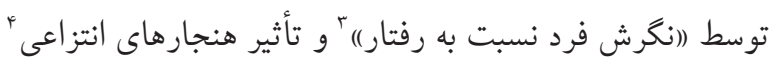

افراد كه در زندكى فرد قابل توجه هستند تعيين مىشود (1) (1).

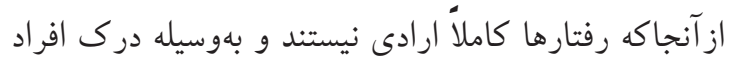

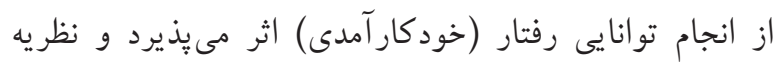
عمل منطقى نمى تواند براى بررسى روابط عقايد بهداشتى كافى ريى

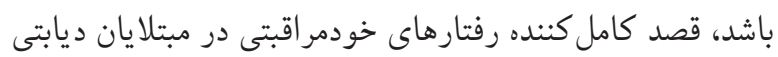
است. بدين منظور نظريه عمل منطقى توسط اضافه كردن جندين

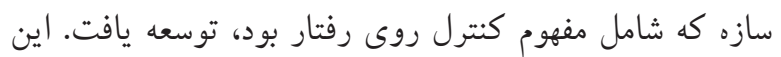
تحقيق ويشنهاد مى كند كه نظر يه عمل منطقى توسعهيافته، علاوه بر هنجارهاى انتزاعى و نكرش، شامل خودكارآمدى بهعنوان تعيين كننده سوم قصد رفتارى نسبت به مفهوم رفتار فرضشيده در نظريه اصلى است. تعدادى از تحقيقات نشان دادهاند كه نظريه

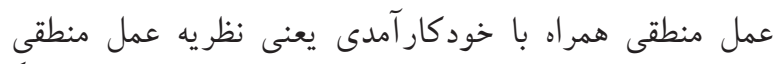

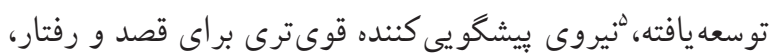

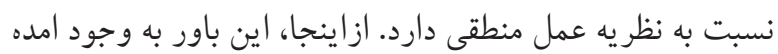

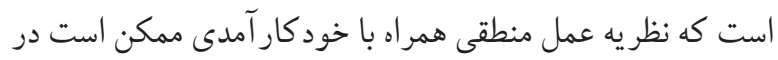
ويشكويى و توضيح رفتار هاى خودمر اقبتى ديابت مفيد باشد (9) (9).

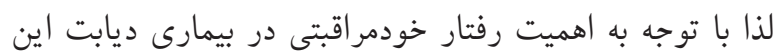

2. Theory Reasoned Action (TRA)

3. Attitude to Act (A act)

4. Subjective Norms (SNs)

5. Extended Theory Reason action (ETRA)
ديابت، يك بيمارى شايع و يرهزينه است و ارتباط معنادارى با

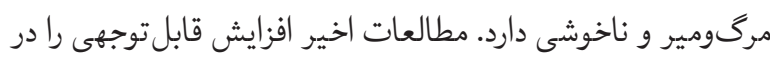

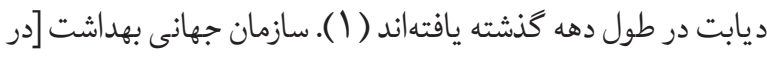

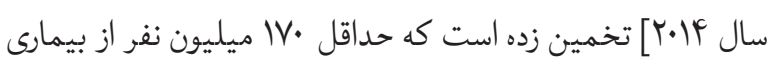
ديابت در سراسر جهان رنج مى برند و اين رقم احتمال دارد تا سال

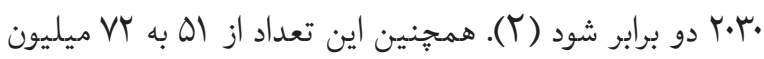

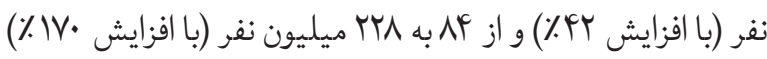
به ترتيب در كشورهاى توسعه يافته و درحالتوسعه افزايش خواهد يافت. ديابت به جندين دليل (ماهيت مزمن بيمارى، عوارض جدى دئ،

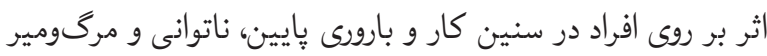

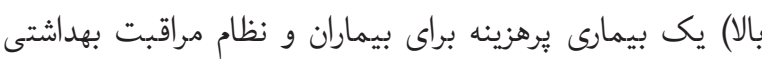

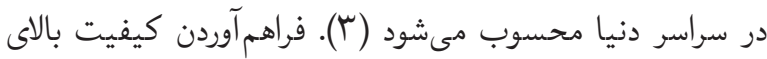

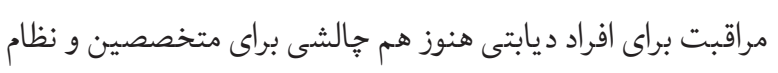

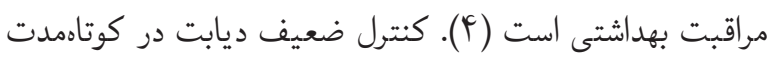
مى تواند باعث كتواسيدوزيس- شرايطى خطرناك و بالقوه كشنده و در درازمدت عوارضى مانند رتينوياتى و نفروياتى در ديابت را افزايش دهد (ه). (ه) - (ه) مديريت موفق ديابتبه منظور كنترل علائم و ويشخيرى از از عوارض بيمارى به انجام اقدامات خودمراقبتى برنامهريزىشده مئه

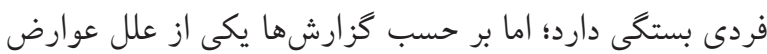
ديابت كمبود خودمراقبتى توسط افراد ديابتى است (9). لذا متخصصان مراقبت بهداشتى از بيماران ديابتى مىخواهند تا بسيارى از رفتارهاى خودمراقبتى را بيشه كنند: تغيير در رزيم غذايى، انجام ورزش، مصرف منظم داروى خود، تزريق انسولين، خوديايشى كلوكز خون، ' تنظيم دوز انسولين، مراجعه منظم در

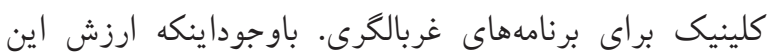

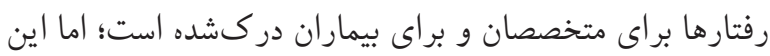

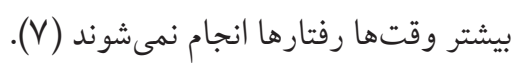

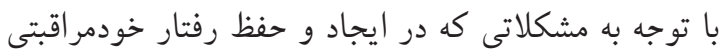

1. Self-Monitoring Blood Glucose (SMBG) 


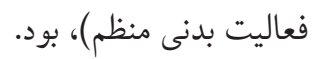
ابزار استفادهده در اين مطالعه يرسشنامه ديدارلو و همكاران

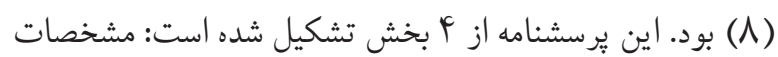
جمعيتشناختى (11 سؤال)، آكاهى (11 سؤال) و ابعاد نظريه

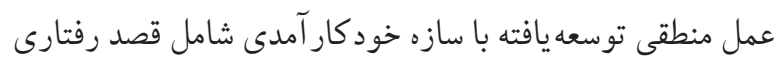

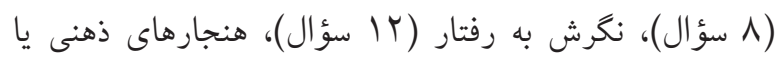

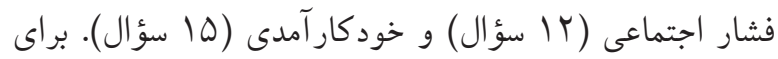
اندازه گيرى رفتارهاى خودمر اقبتى بيماران (رعايت رثزيم غذايى، فعاليت بدنى، مصرف داروهاى ديابت و خوديايشى قند خون) از مقياس خودمر اقبتى فعاليت توبرت و همكاران استفاده شد.

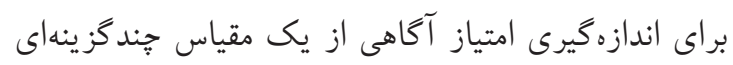

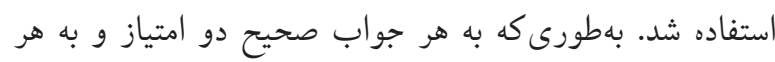

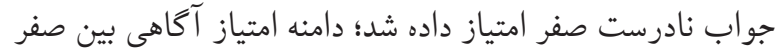
تا TY بود. براى سنجش وضعيت امتياز ابعاد مدل ييشنهادى از مقياس ليكرت ه درجهاى استفاده شد؛ كه از امتياز ا (كاملاً

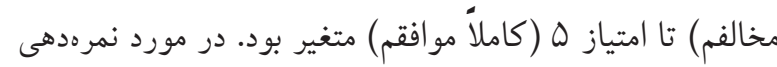

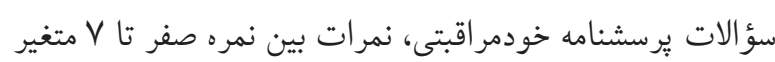

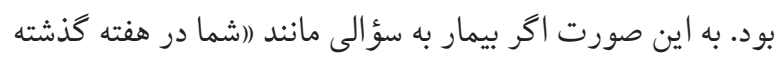

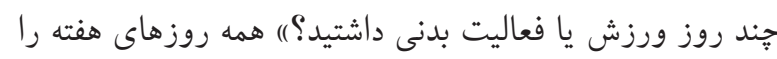

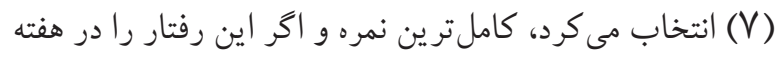

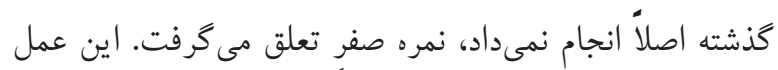

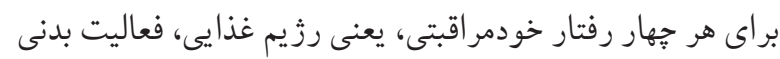
يا ورزش، مصرف داروهاى ضد ديابت و رفتار خود كنترلى قند

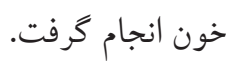
روايى و پايايى علمى اين ابزار در مطالعات قبلى توسط

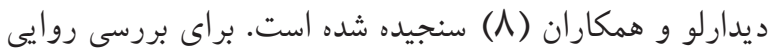
كيفى از پانل متخصصان و براى بررسى روايى كمى از روش روش

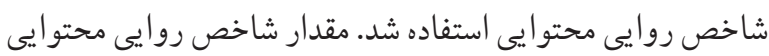

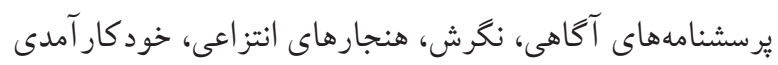

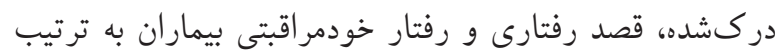

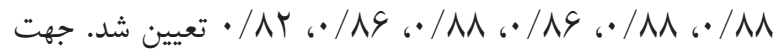

يُزوهش به بررسى نظريه عمل منطقى توسعهيافته در بيشبينى

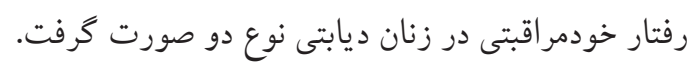

مو اد و روش ها يُزوهش حاضر يك مطالعه مقطعى و توصيفى-تحليلى است.

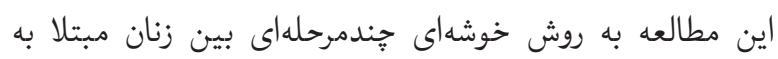
ديابت نوع دو كه به مراكز بهداشتى درمانى دولتى شهر مشهد

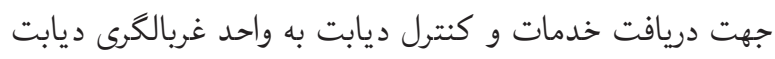

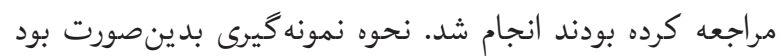

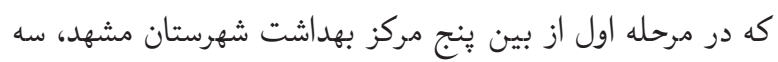

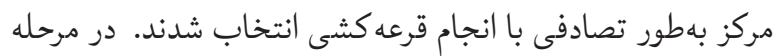

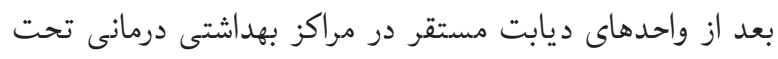
يوشش اين مراكز به روش تصادفى شش مركز بهداشتى درمانى

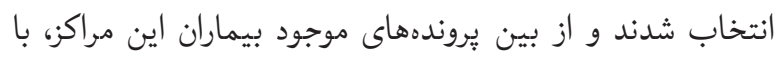
توجه به تراكم جمعيت در هر خوشه و شرايط ورود و خروج از مطالعه، واحدهاى نمونه تعيين گرديدند. حجم نمونه مطالعه جهت

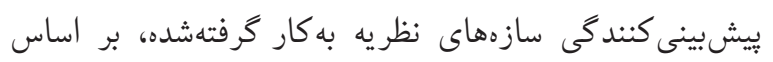

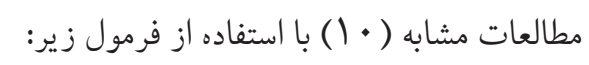

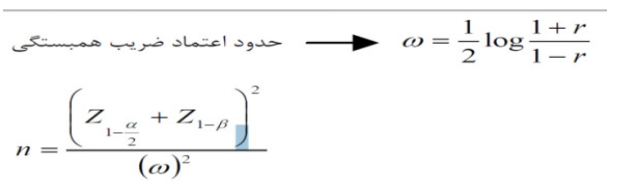

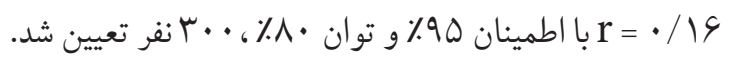
معيارهاى ورود آزمودنىها به مطالعه عبارت بودند ازئ تمايل

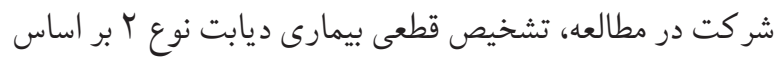
مدارك آزمايشگاهى درجشده در يرونده سلامت بيمار در مراكز

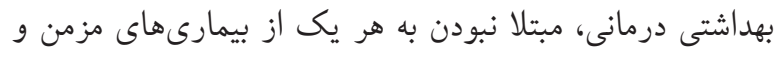

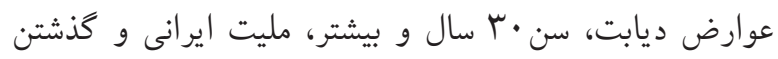

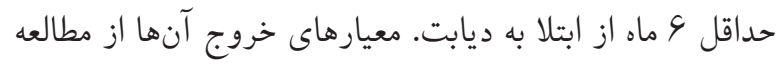

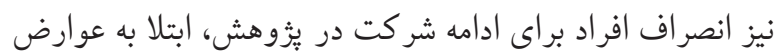

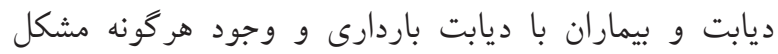

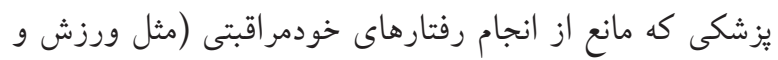




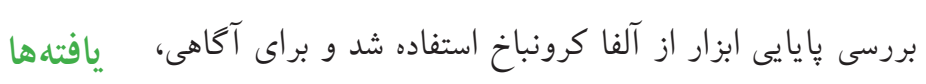
در اين مطالعه ..ب زن ديابتى شركت داشتند. ميانگين سنى اين

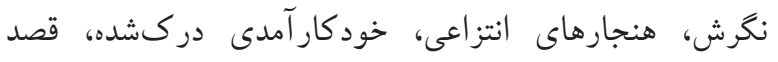

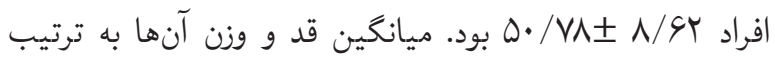

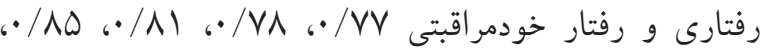

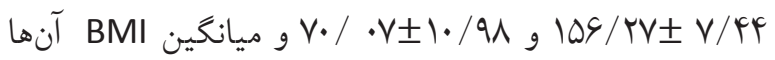

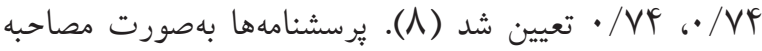

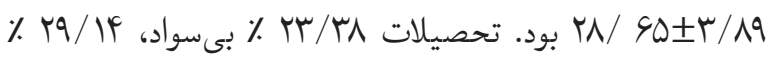

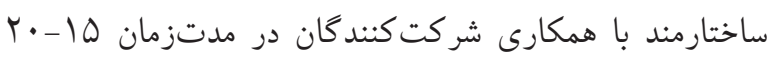

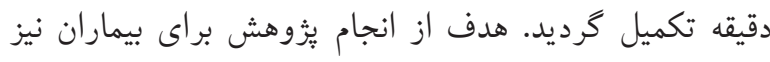
شرح داده شد و پِ از اطمينان بخشيدن در مورد محفوظ ماندن

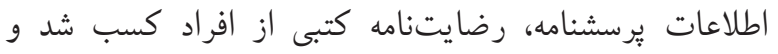
يرسشنامها در ميان بيماران توزيع گرديد.

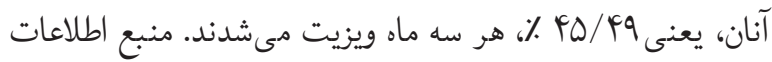

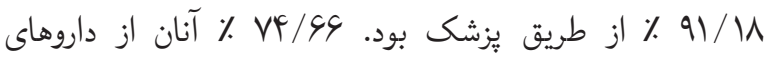

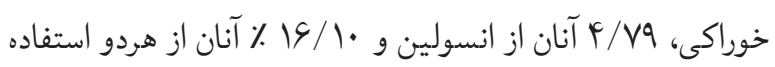

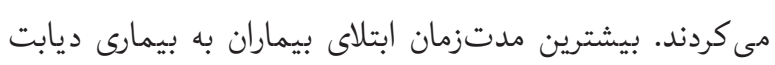

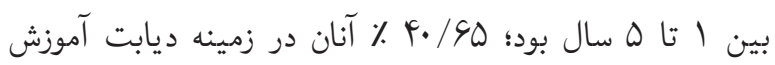
ديده بودند. با توجه به نتايج آزمون كلمو گروف-اسميرنف براى بررسى بودئ

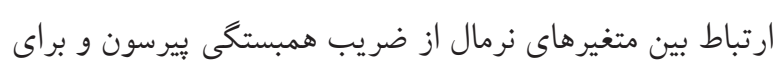

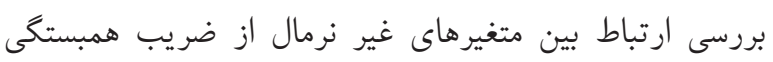

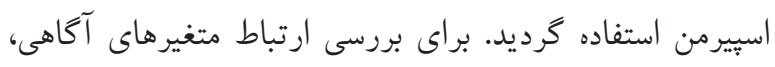

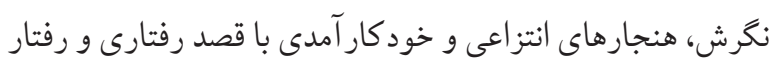

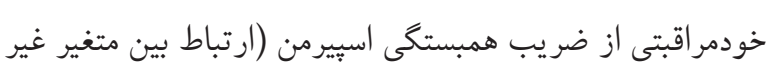

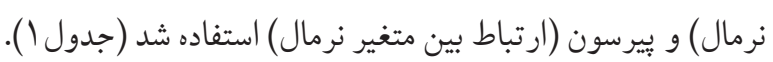

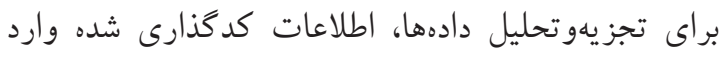

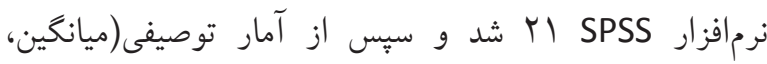
انحرافمعيار) و استنباطى (آزمونهاى پارامتريك تى مستقل

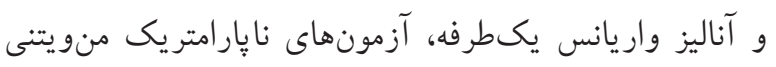

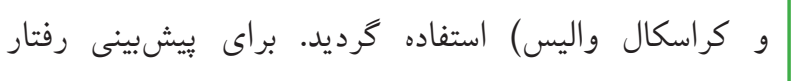
خودمراقبتى بهعنوان متغير وابسته از روى ساير متغيرها از

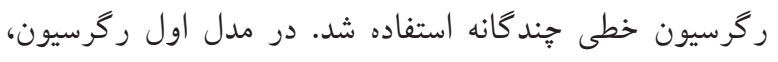

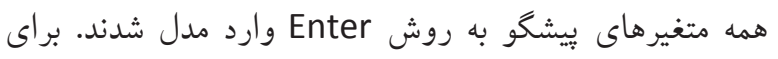
بهينه كردن مدل ركرسيون رفتار خودمراقبتى و كنار كذاشتن

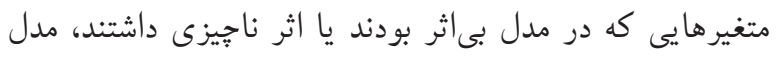

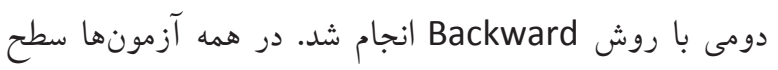
معنادارى ه • • • در نظر كرفته شد.

جدول ا. بررسى ارتباط متغيرها با قصد رفتارى و رفتار خودمراقبتى با استفاده از ضريب همبستگى اسييرمن و وييرسون

\begin{tabular}{|c|c|c|c|c|c|c|c|}
\hline \multicolumn{3}{|c|}{ رفتار خودمراقبتى } & \multirow{2}{*}{ متغير } & \multicolumn{3}{|c|}{ قصد رفتارى } & \multirow{2}{*}{ متغير } \\
\hline نوع آزمون & p value & ضريب & & نوع آزمون & p value & ضريب & \\
\hline ي ييرسون & $<\cdot / \cdot \cdot 1$ & . / YАץ & آكاهى & يیير سون & $<\cdot / \cdot \cdot 1$ & $\cdot / \mu \cdot \Lambda$ & آكاهى \\
\hline اسِيرمن & $\cdot / \cdot r$ &.$/ 189$ & ن نكرش & اسييرمن & $<\cdot / \cdot \cdot 1$ &.$/ r \Delta q$ & نكرش \\
\hline اسِيرمن & $\cdot / \cdot 1$ & $\cdot / r \cdot \Delta$ & خود كار آمدى & اسييرمن & $<\cdot / \cdot \cdot 1$ & $\cdot / \Delta \Delta F$ & خود كار آمدى \\
\hline اسِيرمن & $.1 . s q$ & .1110 & هنجارهاى انتزاعى & اسييرمن & $<\cdot / \cdot \cdot 1$ & ס & هنجارهاى انتزاعى \\
\hline
\end{tabular}

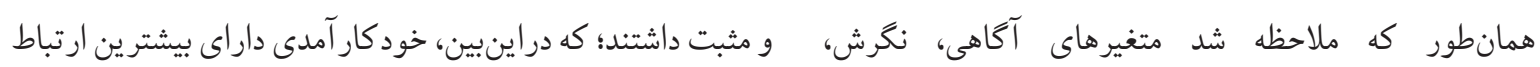

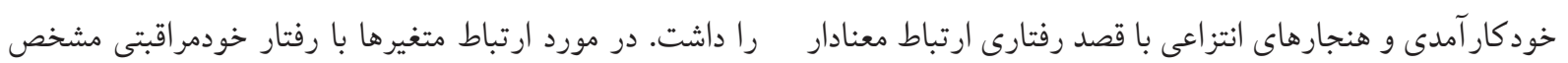


براى بهينه كردن مدل رگرسيون قصد رفتارى و كنار گذاشتن متغيرهايى كه در مدل بىاثر بودند يا اثر ناجيزى داشتند، مدل دومى با روش پسرو انجام شد. در اين روش متغيرها با اثر ناجيز، يكبهيك، از مدل كنار گذاشته شدند تا مدل نهايى بهينهشده بهدست آمد. نتايج آزمون اين مدل در جدول سقابل مشاهده است. در مدل دوم متغيرهاى وضعيت تأهل (فقط وضعيت هاى متأهل و بيوه نسبت به مطلقه)، شغل، وزن، خود كار آمدى و هنجارهاى اجتماعى باقى ماندند و بقيه از مدل كنار كذاشته شدند. با توجه به مقدار مدل، مىتوان كفت اين مدل در صورت وجود ساير p value شرايط براى ييشبينى قصد رفتارى ازنظر آمارى معنادار بوده است. ملاحظه شده ضر يب همبستكى قوى بين متغيرهاى بيشگو با متغير وابسته (قصد رفتارى) وجود دارد (VDr/•). با توجه به ضريب تعيين اصلاحشده مشخص گرديد هه٪ تغييرات قصد رفتارى توسط همين مدل قابل يِيشبينى است. اين نكته نشان داد كه با وجود كنار كذاشتن تعدادى از متغيرها از مدل، دقت مدل كاهش قابلتوجهى نداشته است.

جدولس. نتايج آزمون مدل دوم رگرسيون براى ييشيينى قصد

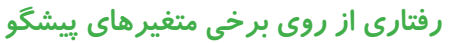

\begin{tabular}{|c|c|c|c|c|}
\hline$p$ value & آماره آزمون & درجه آزادى & مجموع مربعات & تغييرات \\
\hline \multirow[t]{3}{*}{$<\cdot / \cdots 1$} & rr/sqV & 4 & $11 \wedge r / \Delta 9 r$ & رگرسيون \\
\hline & & 10. & $q \cdot \boldsymbol{F} / q \wedge \mu$ & باقيماندهها \\
\hline & & 109 & $r \cdot \Lambda \Lambda / \Delta V \Delta$ & كل \\
\hline \multicolumn{5}{|c|}{ 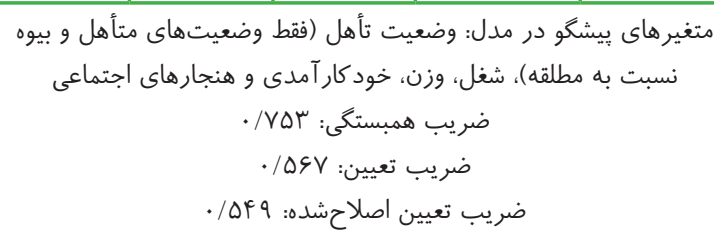 } \\
\hline
\end{tabular}

براى ييشبينى رفتار خودمراقبتى بهعنوان متغير وابسته از روى ساير متغيرها از رگرسيون خطى جندگانه استفاده شد. در مدل اول ركرسيون نيز همه متغيرهاى ييشگو به روش وارد مدل شدند. نتايج آزمون اين مدل در جدول f قابلمشاهده است. با توجه به مقدار p value مدل، مىتوان گفت اين مدل
گرديد همبستگى بين آكاهى، نكرش و خود كار آمدى با رفتار خودمراقبتى معنادار و مثبت بود. بهعبارتديگر، افراد با آكاهى، نگرش و خود كار آمدى بيشتر رفتار خودمراقبتى بيشترى داشتند. ارتباط هنجارهاى انتزاعى با رفتار خودمر اقبتى معنادار نبود. براى ييشبينى قصد رفتارى و رفتار خودمراقبتى، بهعنوان متغيرهاى وابسته از روى ساير متغيرها، از ركرسيون خطى جند گانه استفادهشد. متغيرهاى تحصيلات، وضعيت تأهل، آموزش، شغل، درآمد، سن، قد، وزن، BMI، آكاهى، نگرش، خود كار آمدى و هنجارهاى انتزاعى بهعنوان متغيرهاى ييشگو يا مستقل در نظر كرفته شدند. در مورد متغيرهاى كيفى دوحالته، سطوح آنها به حالت صفر و يك تغيير داده شد تا در مدل ركرسيونى قابلاستفاده باشند. براى متغيرهاى كيفى بيش از دو حالت (مثل تحصيلات و وضعيت تأهل)، از متغيرهاى نشانكر استفاده شد. در مدل اول رگرسيون، همه متغيرهاى بيشخو به روش Enter وارد مدل شدند. نتايج آزمون اين مدل در جدول r قابل مشاهده است. با توجه به مقدار p value مدل، مىتوان كفت اين مدل در صورت وجود ساير شرايط براى بيشبينى قصد رفتارى ازنظر آمارى معنادار بوده است. همانطور كه ملاحظه شد ضريب همبستخى قوى بين متغيرهاى ييشخو با متغير وابسته (قصد رفتارى) وجود دارد (VV9/•). با توجه به ضريب تعيين اصلاحشده، مشخص گرديد هه٪ تغييرات قصد رفتارى توسط همين مدل قابل ييشبينى است.

جدولr. نتايج آزمون مدل اول رگرسيون براى ييشبينى قصد

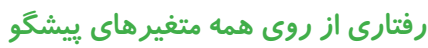

\begin{tabular}{|c|c|c|c|c|}
\hline p value & آماره آزمون & درجه آزادى & مجموع مربعات & منبع تغييرات \\
\hline \multirow[t]{3}{*}{$<\cdot / \cdot \cdot \mid$} & $11 / 0 \mathrm{Vr}$ & 11 & $\mid r \Delta S / D \cdot r$ & 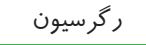 \\
\hline & & $\mid r k$ & $\Lambda \mathrm{r} / \cdot \mathrm{Vl}$ & باقيماندهها \\
\hline & & 109 & $r \cdot \Lambda \Lambda / \Delta V \Delta$ & كل \\
\hline \multicolumn{5}{|c|}{ 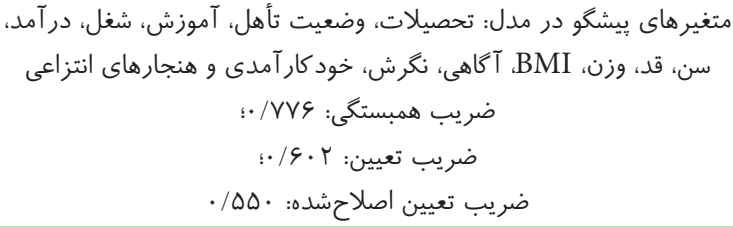 } \\
\hline
\end{tabular}


جدول ه. نتايج آزمون مدل دوم ركرسيون براى يِيشينى رفتنار

خودمر اقبتى از روى برخى متغير هاى بيشكو

\begin{tabular}{|c|c|c|c|c|}
\hline$p$ value & آزمون & درجه آزادى & مربعات & تغييرات \\
\hline \multirow[t]{3}{*}{$<\cdot / \cdot \cdot \mid$} & 91.91 & 11 & rssq/0.. & ركرسيون \\
\hline & & IFD & VqV//A.1 & باقيماندهها \\
\hline & & 109 & $\| g F \mid / \mu \cdot 1$ & كل \\
\hline هلمل و بيوه & و ضعيت هاء & 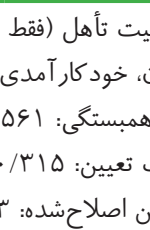 & 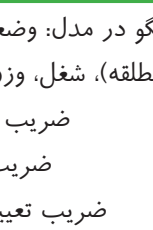 & متغير هاى بي \\
\hline
\end{tabular}

بحث

هدف از انجام اين مطالعه، بررسى و شناسايى عوامل مؤثر بر

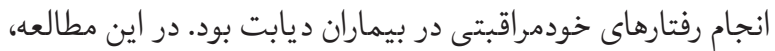

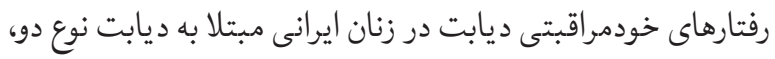
براى درك بيشتر عواملى كه بر رفتارهاى خودمراقبتى تأثيركذار هستند با استفاده از نظريه عمل منطقى توسعه يافته بررسى شدند.

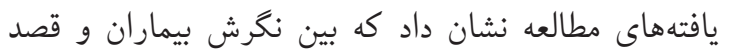

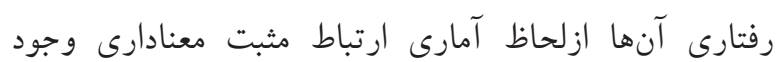

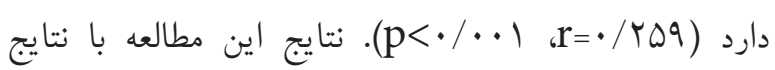

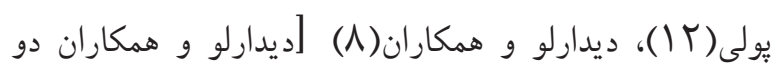

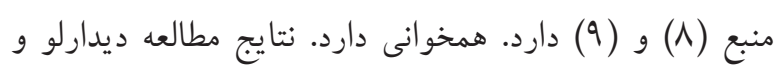
همكاران (9) با عنوان ("يشيخويى رفتار خودمديريتى در ميان

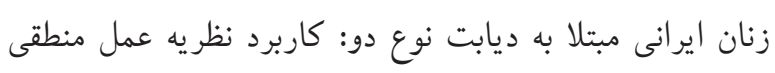
همر اه با خودكار آمدى)) نشان داد كه رابطه مثبت معنادارى ميان

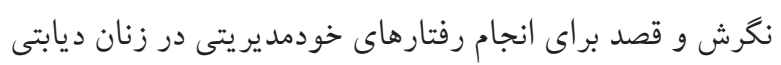

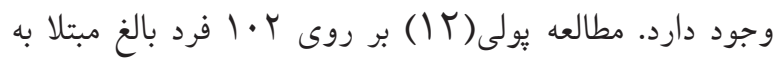
ديابت شيرين (مليتوس) غيروابسته به انسولين نشان داد كه بين باورهاى بهداشتى و رفتار خودمديريتى ديابت رابطه معنادار

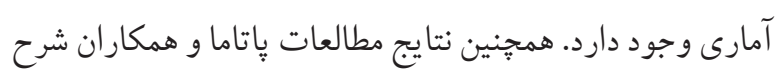

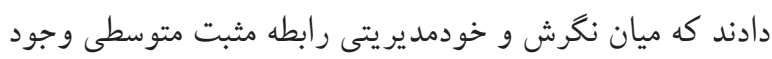

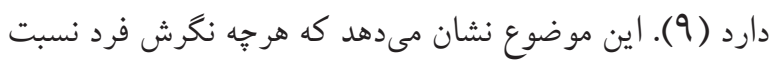

در صورت وجود ساير شرايط براى بيشبينى رفتار خودمراقبتى

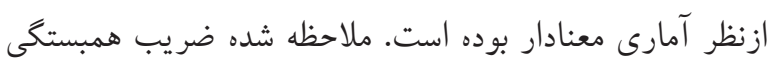
متوسط بين متغيرهاى بيشكو با متغير وابسته (رفتار خودمراقبتى)

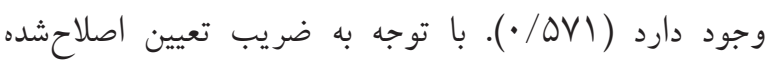

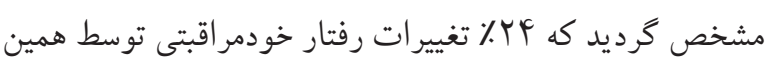
مدل قابل وييشبينى است.

جدول ع. نتايج آزمون مدل اول ركَرسيون براى ييشبينى رفتار خودمراقبتى از روى همه متغيرهاى ييشگُ

\begin{tabular}{|c|c|c|c|c|}
\hline p value & آماره آزمون & درجه آزادى & مجموع مربعات & تغييرات \\
\hline \multirow[t]{3}{*}{$<\cdot / \cdot .1$} & $r / v I V$ & 11 & rᄉ../qץr & , كرسيون \\
\hline & & Ir & $\checkmark \wedge \uparrow \cdot / r \Delta \Lambda$ & باقيماندهها \\
\hline & & 109 & ||$s 4 \mid / \mu \cdot 1$ & كل \\
\hline \multicolumn{5}{|c|}{ 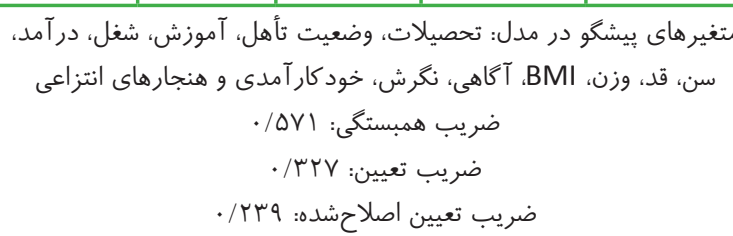 } \\
\hline
\end{tabular}

براى بهينه كردن مدل ركرسيون رفتار خودمراقبتى و كنار

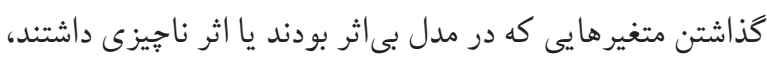

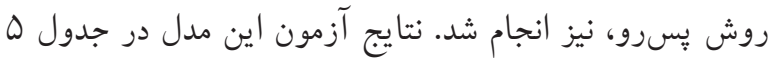

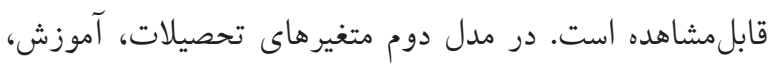
شغل، قد، وزن، BMI، آكاهى و خود كار آمدى باقى ماندند و بقيه از مدل كنار كذاشته شدند. با توجه به مقدار مىتوان كفت اين مدل در صورت وجود ساير شرايط براى ييشبينى رفتار خودمراقبتى ازنظر آمارى معنادار بوده است.

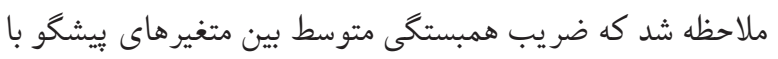

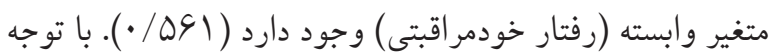
به ضريب تعيين اصلاحشده، مشخص گرديد كه وب٪ تغييرات رفتار خودمراقبتى توسط همين مدل قابل يبشبينى است. اين

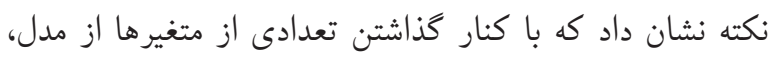
دقت مدل بهبوديافته است. 
به كسانى كه نمىدانستند، داشتند. به نظر مىرسد آسان ترين دليل قابل حل براى انجام ندادن رفتارهاى درست خودمراقبتى فقدان دانش باشد. باينوجود، در يك فراتحليل بر روى •r مطالعه

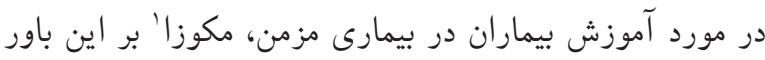

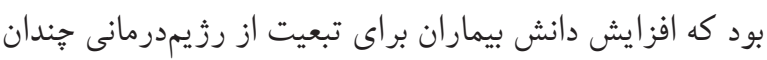
كافى به نظر نمىرسد. همجينين در مورد مصرف دارو، درئ دريك

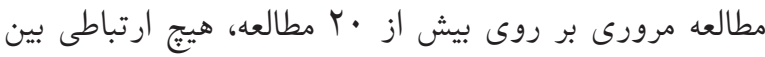

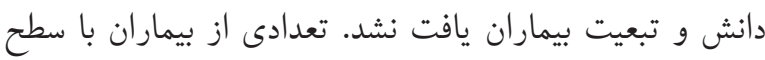

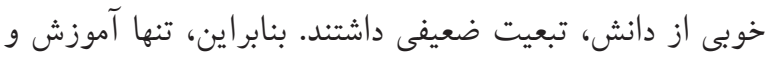

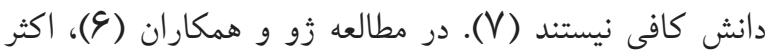

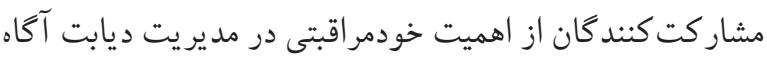

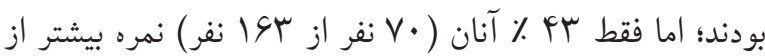

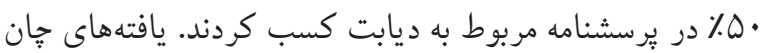

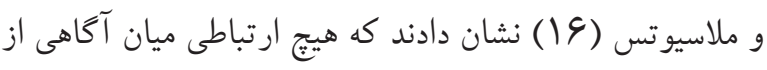

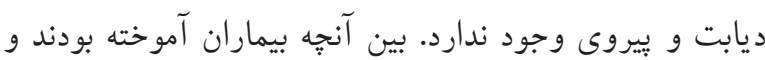

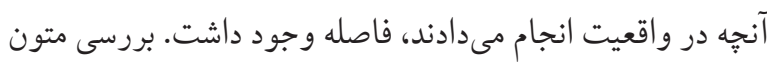

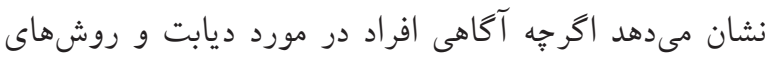

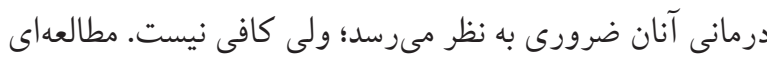
بيشنهاد مى كند كه بهمنظور ارتقاى رفتارهاى خودمراقبتى در بهر

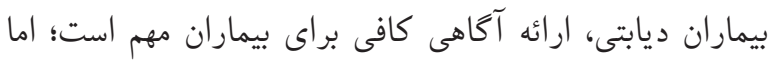

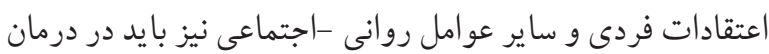

$$
\text { اين بيمارى مدنظر قرار كيرند (1). }
$$

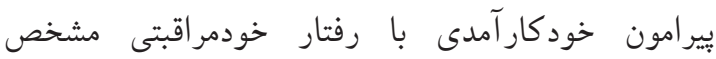

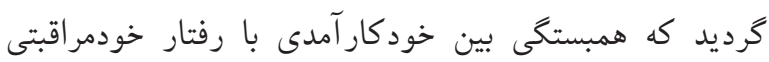

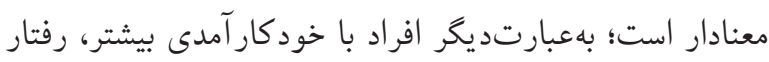

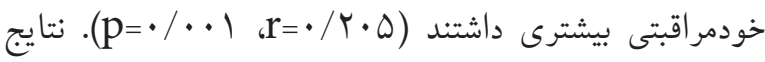
يافتهاى اين يزوهش با نتايج مطالعات هارلى و شى (IV) (IV)،

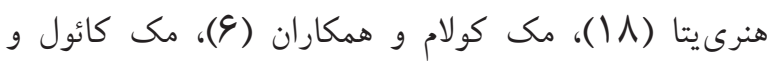

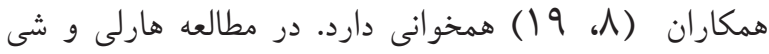
(IV)
به رفتارهاى خودمراقبتى ديابت قوىتر بيشتر باشد، احتمال قصد افر اد براى انجام رفتارهاى خودمراقبتى بيشتر مىشود. در بررسى سازه فشار اجتماعى يا هنجار انتزاعى با قصد

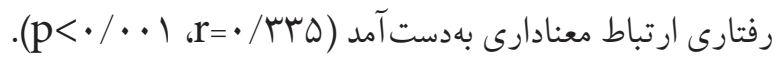
نتايج اين مطالعه با يافتهاى فيشمن (I (I) و ديدارلو و همكاران

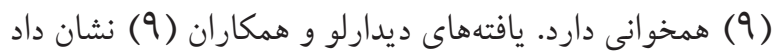
كه هنجارهاى انتزاعى با قصد رفتارى رابطه مثبتى داشتند. در يُزوهش فيشمن (س ( ) با عنوان (ا •9 ثانيه مداخله: تبعيت بيمار

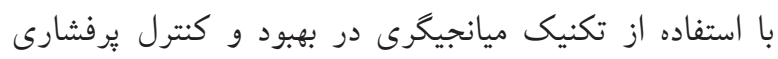

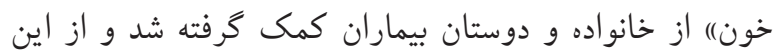
حقيقت استقبال شد كه حمايت اجتماعى نقش كليدى در ارتقاء سلامت، كاهش استعداد ابتلا به بيمارى و تسهيل بهبود بيمارى ايفا مى كند. اما در مطالعه جليبوى و كاروين (IF) ("تأثير حمايت اجتماعى، خودكارآمدى و وييامدهاى انتظار بر ونى

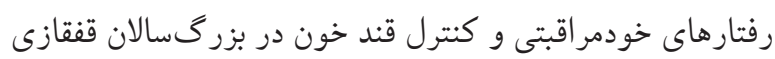
و آفريقايى آمر يكايى مبتلا به ديابت نوع دوا)، هيج ارتباطى ميان حمايت اجتماعى با رفتارهاى خودكار آمدى و كنترل كليسميك،

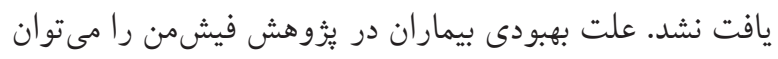
ارائه برنامه حمايتى و مؤثر بودن اين برنامه توسط خانواده و

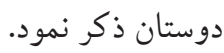
از طرفى ديكر، بين متغير آكاهى گرفتار خودمراقبتى رابطه آمارى مثبت معنادارى مشاهده شد ( (p) نتايج اين مطالعه با يافتهاى ديدارلو و همكاران (1-9) و و هيسلر و همكاران (ه ( ) همخوانى دارد. در مطالعه ديدارلو و همكاران

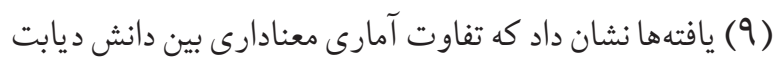
و رفتار خودمراقبتى وجود دارد. اينطور كزارششده كه يك

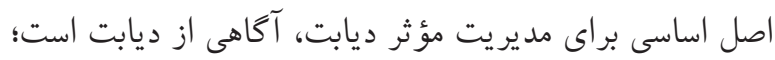

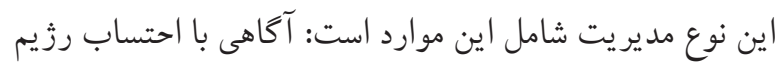
صحيح ، دارو و خوديايشى كلوكز خون (9). در مطالعه هيسلر و

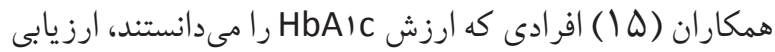
و فهم بهترى رادر مراقبت از ديابت در كنترل كليسميك نسبت 
نيز خودكار آمدى بهعنوان ييشبينى كننده قدرتمند قصد رفتارى

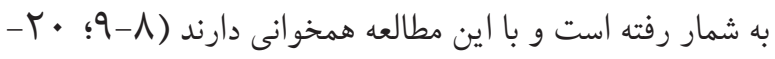

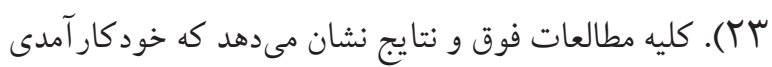
سازهاى مؤثر در ارتقاء قدرت بيشبينى كنندگى و برازش مطلوب نظر يه موردنظر است.

نتيججه گيرى: با توجه به مطالب ذكرشده، مى توان نتيجه كرفت كه

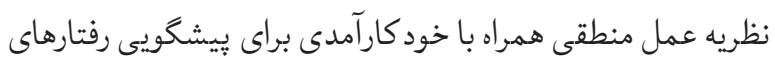

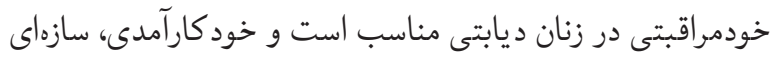
مهم در تعيين رفتارهاى خودمراقبتى به شمار مىرود. همجنين ازآنجاكه خودكارآمدى از ميان ساير متغيرها، داراى بيشترين

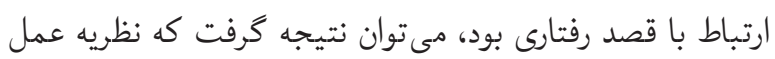
منطقى توسعهيافته نسبت به نظريه عمل منطقى از كارايى بيشترى برخوردار است.

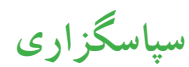
يُزوهشكران بر خود واجب مىدانند از مسئولين و كاركنان دانشخاه علوم يزشكى مشهد و كليه بيماران و عزيزانى كه مسير اين يُوهش را بر ما هموار كردند، كمال قدردانى را به عمل آورند.

\section{Reference:}

1. Norris S, Lau J, Schmid C, Engelgau M.Self-Management Education for Adults With Type 2 Diabetes. DIABETES CARE 2002;25(7).

2. Lin $E$, Katon $W$, Von korff M, RUTTER C, SIMON G and ea tal . Relationship of Depression and Diabetes Self-Care, Medication Adherence, and Preventive Care. Diabetes Care 2004;27(9):2154-60.

3. Abazari P, Vanaki Z, Mohammadi E, Amini M. Challenges of training diabetes nurse educator in Iran. Iran J Nurs Midwifery Res 2012;17(3):187-b94.

4. Worswick J, Wayne C, Bennett R, Fiander M, Mayhew A, Weir M.C, Sulliva K, Grimshaw J.M. Improving quality of care for persons with diabetes: an overview of systematic reviews - what does the evidence tell us? Bio Med Central 2013;2(26).

5. Loveman E, Cave C, Green C, Royle P, Dunn N, Waugh N. The clinical and cost-effectiveness of patient education models for diabetes: a systematic review and economic evaluation. Health Technology Assessment 2003;7(22).
در افراد با نيازهاى ويبحيده انسولينى ارتباط داشت. افراد با

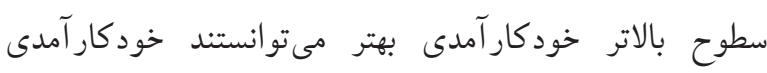

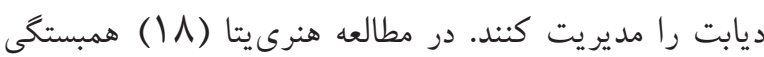

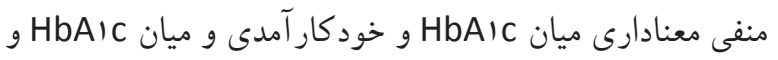

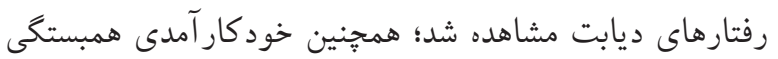

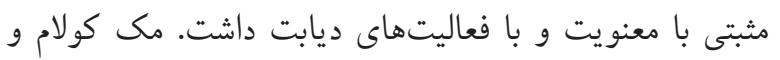

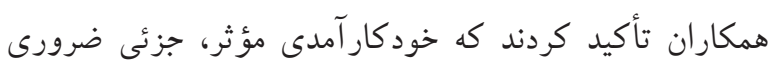

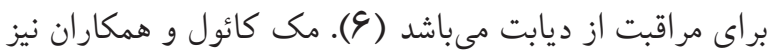
كه رفتارهاى رزيم ديابتى را بررسى نمودند، همبستكى معنى دئادار

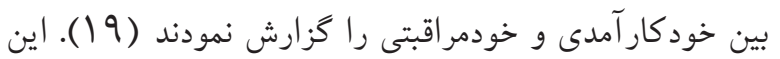

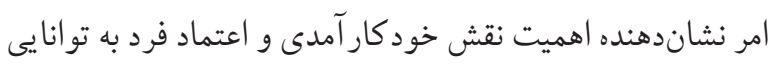
خود در انجام رفتارهاى خودمراقبتى است.

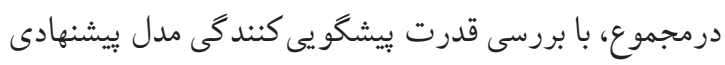

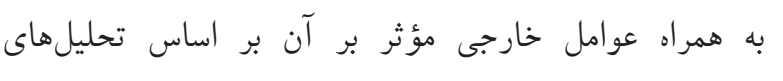

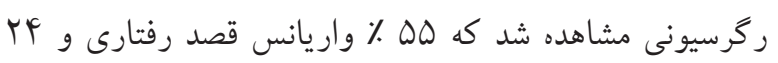
٪ واريانس رفتار خودمر اقبتى بهوسيله مدل فوق تبيين مى گرد دد. همجنين ملاحظه شد كه خودكار آمدى تأثير بيشترى روى قدى قصد

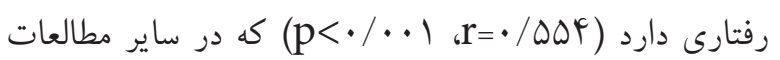

6. Zhou $Y$, LiliaO, Meisun, Gouping HE. Self-care practices of Chinese individuals with diabetes. exprimental and therapeutic medicine 2013;5: 1137-42.

7. Harvey J. N., Lawson V. L. The importance of health belief models in determining self-care behaviour in diabetes. Diabetic Medicine2009;26:5-13.

8. Didarloo AR, Shojaeizadeh D, Ardebili H, Niknami SH, Hajizadeh E, Alizadeh M. Factors Influencing in selfcare Behavior among Iranian Women with Type 2 Diabetes reffer to Khoy city clinic on base Extended Theory of Reasoned Action.Journl Health school \& Anisttitue health research2011;9(2):79-92

9. Didarloo AR, Shojaeizadeh D, Gharaaghaji R, Habibzadeh H, Niknami Sh, Pourali R. Prediction of Self-Management Behavior among Iranian Women

10. with Type 2 Diabetes: Application of the Theory of Reasoned Action along with

11. Self-Efficacy (ETRA). Iranian Red Crescent Medical Journal2012;14(2):86-95

12. Tehrani, H., Determining the Theory of Planned Behavior's 
Predictive Power on Adolescents' Dependence on Computer Games. Iranian Journal of Health Education and Health Promotion, 2015. 2(4): p. 303-311.Montano D, Taplin S. A test of an expanded theory of resoned action to pridict mammography participation. Sot Sri Med1991;32(6): 733-41.

13. Polly RK. Diabetes health beliefs, self-care behaviors, and glycemic control among older adults with non-insulindependent diabetes mellitus. The Diabetes Educator. 1992 Aug 1;18(4):321-7.

14. Fishman $T$. The 90-Second Intervention: a patient compliance mediated technique to improve and control hypertension. Public Health Reports 1995;110(2):173-8.

15. Chlebowy DO, Garvin BJ. Social support, selfefficacy and outcome Exeptions: impact on selfcare behaviors and glycemic control in Caucasian and African American adults with type 2 diabetes. Diabetes Educator. 2006;32(5): 77786

16. Heisler M, Piette J.D, Spencer M, Kieffer E, Vijan S. The Relationship Between Knowledge of Recent HbA1c Values and Diabetes Care Understanding and Self-Management. Diabetes Care2005;28(4):816-22.

17. Chan YM,Molassiotis A. The relationship between diabetes knowledge and compliance among Chinese with non-insulin dependent diabetes mellitus in Hong Kong. Journal of Advanced Nursing 1999;30(2):431-8.
18. Hurley A.C, Shea C.A. Self-Efficacy: Strategy for Enhancing Diabetes Self- Care. Diabetes EducatorJ1992;18(2):146-50.

19. Henrietta $\mathrm{H}$. The influence of self-efficacy and spirituality on self-care behaviors and glycemic control in older African Americans with type 2 diabetes (Dissertations \& Theses) 2006; BARRY UNIVERSITY SCHOOL OF NURSING:182.

20. Mccaul KD, Glassgow RE, Schafer LC. Diabetes regimen behaviors predicting adherence.Med Cre1987;25(9):86881.

21. Giles M, McClenahan C, Cairns E, Mallet J. An application of the Theory of Planned Behaviour to blood donation: the importance of self-efficacy. Health Educ Res 2004 ;19:380-9.

22. Tolma EL, Reininger BM, Evans A, Ureda J. Examining the theory of planned behavior and the construct of self efficacy to predict mammography intention. Health Educ Beha journal2006;33:233-51.

23. Broadhead-Fearn D, White KM. The role of self-efficacy in predicting rule-following behaviors in shelters for homeless youth: a test of the theory of planned behavior. J Soc Psychol 2006;146:307-25.

24. Norman P, Hoyle S. The Theory of Planned Behavior and Breast Self-

25. Examination: Distinguishing Between Perceived Control and Self-Efficacy. Journal of Applied Social Psychology 2004;34:694-708. 